\title{
FORME RELIGIOASE NOI CAUZATE DE PREZENȚA RELIGIEI ÎN MEDIUL VIRTUAL
}

Andrei Ovidiu Crişan*

\begin{abstract}
In present article I have demonstrated that the presence of religion in the virtual space can cause occurance of rather distorted religious forms compared to the current religious pattern. Even the traditional religions can come into shapes which are in conflict with religious authorities. Internet use by religions is a positive thing, but it should remain a tool, not a environment. I have also shown, in the present article, that there is the tendency to revitalise the paganism through internet using, but the exotism of the matter is the junction between SF litterature or cinema and online religion.
\end{abstract}

Keywords: history of religions, new religious mouvements, cyberreligion, virtual religion, globalizaton, church and media, internet.

\section{Preliminarii}

După cel de-al Doilea Război Mondial lumea a avut parte de o sumedenie de schimbări pe toate planurile. Principala cauză a acestor schimbări este profunda preocupare a omului față de ştiință, educație, cercetare, etc., conducând, deseori la rezultate inimaginabile. Printre aceste realizări regăsim şi apariţia tehnologiei informaţiei şi a calculatorului. Marshall McLuhan considera că „o societate este definită şi caracterizată de elementele tehnologice, în special cele ce țin de comunicare, deoarece omul poate să $\hat{\imath} s ̧ i$ transmită stările, experimentele, gândirea, etc., celorlalți oameni, formându-şi o

\footnotetext{
* PhD candidate, "1 Decembrie 1918" University of Alba Iulia, Romania.
} 


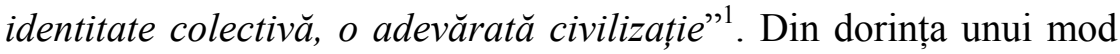
facil de comunicare a apărut în anul 1969 o rețea a mai multor rețele „network of networks" numită Arpa care făcea legătura între rețelele câtorva universități din vestul $\mathrm{SUA}^{2}$. Prin urmare, din acest moment evoluția internetului a ajuns la cote inimaginabile. Este evindent faptul că omul nu a rămas imun la aceste metomorfoze postbelice, drept pentru care astăzi suntem martorii unui comportament schimbat, în decursul ultimelor şapte decenii, schimbare nemaiîntâlnită în întreaga istorie a omenirii.

Mircea Eliade a încercat în toată cercetarea lui să demonstreze că omul este ființă eminamente religioasă - homo religiosus, însă în ultimul timp avem de-a face cu o nouă ,particularitate” numită homo interneticus. În acest articol intenționăm să evidențiem trăsături comune celor două caracteristici ale ființei umane. Dorința noastră este a arăta că există forme de religiozitate exclusiv virtuale, care intră în categoria noilor mişcări religioase.

Una dintre cele patru subteme ale simpozionului nostru este relația dintre mass media şi misiunea Bisericii, iar acest articol are intenția de a expune denaturări ale relației dintre Biserică, religie, spațiu sacru şi lumea virtuală. Dorim să demonstrăm că apariția formelor religioase din spaţiul virtual reprezintă un risc pentru creştinism. Biserica are nevoie de internet, dar fără să-şi modifice doctrina, morala şi cultul, or, ceea ce regăsim astăzi în „piața religoasă" Occidentală, sunt manifestări religioase în mediul virtual care nu mai au nimic în comun cu credința creştină. Probabil intențiile promotorilor lor au fost bune, considerând că astfel religia devine accesibilă (la un click distanță de om), însă au sfârşit denaturând grosolan comportamentul sacral.

În acest articol ne propunem să desluşim întrebări cu privire la istoricitatea acestori mişcări, amploarea lor, relația cu formele tradiționale religioase, noutatea pe plan religios adusă de respectivele

\footnotetext{
${ }^{1}$ Marshall Mc Luhan, The Gutenberg Galaxy: the making of typographic man, First Edition, Toronto, University of Toronto Press Incorporated, 1962, passim ${ }^{2}$ A se vedea pagina http://www.computerhistory.org/internet_history/
} 
forme şi anumitele preconizări despre dezvoltarea fenomenului mai sus amitit.

\section{Istoricitatea şi evoluția cyberreligiei}

Mediul virtual a însemnat pentru lumea modernă cel mai facil instrument de masificare a informației. De acest fapt era conştient şi Papa Ioan Paul al II - lea care îndemna la folosirea mijloacelor de comunicare oferite de computer în vederea îndeplinirii misiunii Bisericii în zilele noastre, care reprezintă o nouă formă de evanghelizare ${ }^{3}$. Nu după multă vreme, Biserica Catolică îşi deschide propriul Web site (www.vatican.va) în anul $1995^{4}$. Atenția noastră se îndreaptă în special spre formele religioase care ,înfloresc” în mod exclusiv în mediul virtual. O formă incipientă pseudo-religioasă cu caracter virtual este cea „confecționată” de Ellie Crystal care în anul 1989 şi-a cumpărat propriul calculator, folosindu-1 pentru a transcrie mesajele primate de la o entitate dintr-o altă lume numită „Z”, iar în 1995 şi-a gândit propriul site (www.crystalinks.com) prin care să-şi expună noile sale învăţături religioase şi spirituale ${ }^{5}$. Această pagină a fost punctul de plecare spre o adevărată revitalizare în special a păgânismului, prin crearea unor comunități în jurul paginilor Web. Mixtura dintre păgânism şi ocultism a dat naştere la adrese web ca:

\footnotetext{
${ }^{3}$ Papa Ioan Paul al II-lea, The Christian Message in a Computer Culture, în „Message of Holy Father John Paul II for the 24th World Communcation Day", Libreria Editrice Vaticana, Sunday 27 May 1990, http://w2.vatican.va/content/john-paulii/en/messages/communications/documents/hf_jp-ii_mes_24011990_worldcommunications-day.html, accesat la data de 20.04.2015.

${ }^{4}$ Elena Larsen, Cyberfaith: How Americans Pursue Religion Online, în „Religion Online: Finding Faith on the Internet”, Lorne L. Dawson, Douglas E. Cowan (edd.), New York and London, ed. Routledge, 2004, p. 25.

${ }^{5}$ Site-ul www.crystalinks.com a cunoscut o remarcabilă notorietate de-a lungul celor două decenii de existen ă, ajungând în zilele noastre la 200000 de vizitatori pe zi.
} 
Vocea Vrăjitoarelor (witchvox.com), The Pagan Webcrafters' Association (thepwa.net), sau The Dance (thedance.com), s..a. ${ }^{6}$ care se vreau a fi noi sisteme religioase sincretiste care dețin elemente doctrinare, morale şi cultice.

$\mathrm{Cu}$ siguranță că numărul paginilor $W e b$ de acest fel a cunoscut un trend crescător, direct proporțional cu utilizatorii acestora. Joncțiunea cyberspace-ului cu formele ancestrale religioase, în special cele apuse, au devenit atractive mai ales pentru tinerii internauți. Din analiza făcută de noi pentru acest studiu, nu găsim informații elocvente pentru un procentaj sau număr exact al siteurilor sau aderenților cyberreligiei. Fenomenul cyberreligiei este întrun stadiu incipient aniversând doar 20 de ani.

\section{Religion Online şi Online Religion}

Apariția internetului a reprezentat o schimbare a modului de manifestare a „religiosului”, în sensul că religiile au utilizat atât modul de comunicare online cât şi site-urile, din dorinţa unei mai bune comunicări cu proprii credincioşi, sau chiar cu cei dinafară. Utilizarea internetului ca mijloc fără ca religia să-şi schimbe ceva în esența ei, conduce spre locuțiunea „religion online”, în schimb, pe lângă deschiderea normală spre mediul virtual a religilor consacrate, constatăm că internetul poate să creeze noi forme religioase care sunt „disponibile” doar pe internet, acesta devenind un adevărat mediu pentru ele. În aceste sens, topica expresiei de mai sus se inversează dând naştere unei expresii noi „online religion”, care denotă stricta dependenţă dintre mediul virtual şi respectivele mişcări ${ }^{7}$. Prin urmare, avem de-a face cu Noi Mişcări Religioase (NRM), în care

\footnotetext{
${ }^{6}$ Christopher Helland, Popular religion and the World Wide Web: a Match Made in (Cyber) Heaven în Religion Online..., pp. 27-29.

${ }^{7}$ Fabrizio Vecoli, La religione ai tempi del web, Roma, Editori Laterza, 2013, pp. 63-65.
} 
fiecare individ poate să devină membru fără obligativitatea păstrării unei identități reale ${ }^{8}$.

Sigur că multe religii se folosesc de internet pentru o mai bună deschidere față de oameni, fără a denatura nici esența doctrinei nici modul de asumare a lor de către adepți, însă în ultima perioadă chiar religiile consacrate au dat naştere unor adevărate secte care sunt compuse din comunități virtuale. Unii văd o oportunitate în crearea unei comunități virtuale pentru a compensa frecvența redusă a credincioşilor la cultul oficial ${ }^{9}$.

Constăm cu stupoare că bunele intenții nu garantează şi rezultate pe măsură, fapt pe care îl întâlnim şi când vine vorba despre prezența religiilor tradiționale în spațiul virtual. În cele ce urmează vom expune câteva denaturări ale religiilor tradiţionale cauzate de neînțelegerea limitelor în folosirea internetului ca mijloc misionar.

\section{Câteva elemente specifice ale cyber-religiei}

Cercetătorii din acest domeniu reliefează unele trăsături pe care le întâlnim la mişcările religioase din mediul online. Metamorfoze ale particularităților tradiționale în ceea ce priveşte identitatea religioasă, comunitatea, autoritatea, practica şi ritualul online şi relaţia dintre noua formă online şi religia de proveniență, reprezintă noutatea de care o să ne ocupăm în cele ce urmează.

Despre comunitatea în rețea putem spune că are „capacitatea” de a denatura ideea de comunitate specifică religiilor tradiționale. Unii afirmă că scopul comunităților online este de a suplimenta rolul celor offline. Spre exemplu, Catedrala Anglicană din Second Life pretinde că deține o relație de colaborare cu Biserica

\footnotetext{
${ }^{8}$ Eileen Barker, In and out of places: Varieties of Religious Locations in a Globalising World, în „Holy Nations and Global Identities: Civil Religion, Nationalism, and Globalisation", Annika Hvithamar, Margit Warburg i Brian Arly Jacobsen (Edd.), Leiden, Boston, Ed. Brill, 2009, p. 249.

${ }^{9}$ Tim Hutchings, The Dis/Embodied Church: Worship, new media and the Body, în „Christianity in the Modern World”, (ed. Giselle Vincett, Elijah Obinna), Farnham, Ashgate, 2014, p. 43.
} 
Anglicană. Comunitățile online facilitează relaţionarea între individ şi instituție ${ }^{10}$. Neajunsurile de ordin religios în comunităţile virtuale, provin de la identitatea falsă pe care internauții pot să o dețină atunci când formează comunităţile virtuale. Chiar dacă accesibilitatea rămâne un lucru pozitiv, se pierde profunditatea. Comunităţile virtuale religioase rămân fidele ideii de gesellschaft (comunitatea relațiilor legiferate într-un mod impersonal), în detrimentul celei de gemeinschaft care pune pe priml loc responsabilizarea persoanei ${ }^{11}$. Comunitatea religioasă reprezintă comuniunea ,adevărului persoanelor care o compun, comunicarea fiind modalitatea de a crea o identitate colectivă a adevărului, prin contribuția fiecărei persoane" Or, în situația de față adepții sau aderenții dețin o falsă identitate, care nu depăşeşte statutul de user. Comunitatea religioasă nu este compusă din useri, ci din persoane. Rolul religiei este tocmai revelarea adevărului personal al omului.

Practica sau cultul online, reprezintă o amestecare de practici a căror formă este este îndreptată spre interior, într-un mod egoist. Internetul este un $h u b$ care permite adepților să aleagă dintr-o largă paletă de practici (cultice), ceea ce li se potriveşte. În acest sens, s-au creat posibilități de meditație, cântare, rugăciune, sau chiar edificarea unor cyber-altare, sanctuare, etc., dând libertate maximă internautului să-şi exprime sentimentele şi comportamentul religioase ${ }^{12}$. Practic, surferul devine capabil să creeze absolut orice formă cultică, dând naştere unui univers religios în care doar el poate să figureze.

Religia apărută în mediul online, întră în conflict cu autoritățile religioase tradiționale. Hibridizarea religioasă provocată de artizanii formelor religioase online a condus la oprobiul exponenților religiilor consacrate $^{13}$.

${ }^{10}$ Heidi A. Campbell, Understanding between Religion Online and Offline in a Networked Society, în ,Journal of the American Academy of Religion”, Martie 2012, Vol. 80, No. 1, pp. 68-72.

${ }^{11}$ Fabrizio Vecoli, op. cit., pp. 128-132.

${ }^{12}$ Heidi A. Campbell, Understanding the Relationship..., pp. 76-77.

${ }^{13}$ Ibidem, pp. 75-76. 
Aşadar, cele mai vulnerabile particularităţi religioase rămân comunitatea şi cultul. Tendința redefinirii acestor aspecte pare să îşi găsească argumentarea în mediul online, care într-un mod ineluctabil acaparează noi şi noi valori care au stat la baza periplului omenirii în istorie.

Tot pe tărâm liturgic găsim şi aspecte cu privire la inițiere baptismală online, care pretinde că edifică o aşa zisă comunitate virtuală ${ }^{14}$.

\section{Forme religioase virtuale provenite din religiile tradiționale}

Asistăm astăzi la apariția de noi comunități virtuale în sânul religiilor consacrate şi care conduc spre o neînțelegere a ideii de comunitate. Mediul virtual devine un spațiu sacru în care se poate dezvolta chiar un cult suficient de hibridizat comparativ cu religiile tradiționale, încât să genereze un conflict cu autoritățile religioase ale vremii.

\section{1. Mișcări apărute din sânul marilor religii}

Astfel, Tim Hutchings de la Universitatea din Durham, într-un articol recent apărut analizează câteva cyber-comunități apărute în spațiul creștin occidental: i-Church (www.i-church.org), St. Pixel (http://www.stpixels.com), E-Church (http://echurchgiving.com/), The Cathedral of Second Life (https://slangcath.wordpress.com/), Live Church TV (http://www.lifechurch.tv/), Church of Fools (http://www.churchoffools.com) $)^{15}$, etc. Un alt site care se doreşte a fi unul dintre mijloacele moderne de propovăduire a Evangheliei este http://powertochange.com/truthmedia/, sau Truth Media care provine din protestantism cu intenția virtualizării experienței spirituale, fiind un „ministeriu tradițional într-un mediu netradițional”, cu 800000 de

\footnotetext{
${ }^{14}$ Tim Hutchings, art. cit., p. 43.

${ }^{15}$ Fabrizio Vecoli, op. cit., p. 39.
} 
vizitatori lunar ${ }^{16}$. Aceşti „misionari” pretind că expun Evanghelia şi crează o comunitate virtuală, dar din câte se pare, nu au ca finalitate aducerea „cyber-creștinilor” în spațiul tradiţional eclesial, ceea ce ne îndreptățeşte să afirmăm că aduce o ofensă ideii de Biserică şi că niciodată un astfel de ,instrument” al convertirii nu poate să creeze o adevărată familie a lui Dumnezeu pe pământ. Este puțin probabil ca adepții religiei online să ajungă creştini de profunzime.

În iudaism găsim o comunitate enclavizată care afirmă că are o prezență în mediul online din anii 80 . Chabad se consideră o sectă iudaică pretinzând că depăşeşte perceptele iudaismului în scopul unei „îmbunătăţiri a lumii”, avansând ideea iminentei sosiri a lui Mesia. Faptul că membrii comunităţii pot să aibă o identitate neclară plasează mişcarea Chabad într-un con de umbră față de iudaismul oficial, sau chiar față de celelalte secte iudaice ${ }^{17}$. Pe de altă parte, latura mistică iudaică Kabbala „se bucură” de o sumedenie de pagini web, care au ca scop oferirea unor informații prețioase pentru cei care doresc să practice meditația respectivă, chiar în mediul online.

În islam găsim ideea unei colonizări în spațiul virtual, care, sub standardul globalizării, pretinde a crea o comunitate virtuală, (o umma virtuală), care scandalizează adepții conservatorismului islamic jihadist împotriva Occidentului şi tehnologiei moderne ${ }^{18}$. Mai întâlnim în mediul virtual chiar posibilitatea de a face pelerinaj virtual, mai exact cu ajutorul paginii www.secondlife.com se poate face un pelerinaj (Hajj) la Mecca mimând pelerinajul real ${ }^{19}$. Este

\footnotetext{
${ }^{16}$ Jayeel Serrano Cornelio, The New Face of Global Evangelism: Virtualizing Spiritual Experience, în „Mediating Piety: Technology and Religion in Contemporary Asia", (Edited by Francis Khek Gee Lim), s. l., Brill Academic Publishers, 2009, pp. 187-188.

${ }^{17}$ Oren Golan, Charting frontiers of online religious communities: The case of Chabad Jews, în „Digital Religion: Understanding Religious Practice in New Media Worlds", (Ed. Heidi A. Campbell), New York, Routledge, 2013, pp. 155-160.

${ }^{18}$ Fabrizio Vecoli, op. cit., pp. 77-78.

${ }^{19}$ Ibidem, p. 123.
} 
evident faptul că tradiționaliştii exclud sub orice fel îndeplinirea ritualurilor în mediile online.

Religiile indiene nu sunt nici ele străine de prezența în mediul online. Hinduismul cunoaşte forme de manifestare în spațiul virtual, iar în acest sens, un foarte bun exemplu îl regăsim în ceremonia numită Puja. Această ceremonie este o „formă cultică care necesită prezentarea «ofrandelor onoarei» zeității". ${ }^{20}$ Puja este un bun exemplu al denaturării practicii religioase survenită în urma transpunerii în mediul online, trecând peste utilizarea simțurilor care ajută întregul corp să savureze grația provenită de la zeitate. În schimb, Cyber - Puja constă doar în existența imaginii unei zeități universale sau specifice pe ecran. Sub aspect empiric, ocazional, se interpretează bhajanele (imne devoționale), iar mai apoi se face pe rând click pe icoane în scopul de a produce efecte care constituie aşanumitele upacharas (daruri oferite zeităţii) ${ }^{21}$. Unii dintre adoratorii puja consideră că nu este nimic greşit în a practica cultul online deoarece „nu există niciun motiv, spun ei, pentru care o zeitate să nu poată sălăşlui în mediul virtual, fără să li se afecteze impuritatea, având un impact pozitiv în acest mediu" 22 Acest exemplu are ca scop acordarea unei identități specifice a juncțiunii dintre hinduism şi mediul online. Sigur că, la fel ca şi în celelalte religii găsim şi aici ecomunități, mai ales în diaspora, care după evrei, dețin al doilea grup de site-uri sau link-uri (în număr de 12) ${ }^{23}$.

În ceea ce priveşte Buddhismul, există o afinitate între această religie şi felul în care internetul neutralizează componenta

${ }^{20}$ Diana Eck, Darśan - Seeing the Divine Image in India, Chambersburg, Anima Books, 1985, p. 89.

${ }^{21}$ Heinz Scheifinger, Hindu Embodiment and the Internet, Aesthetics and the Dimensions of the senses, în „Heidelberg Journal of Religions on the Internet”, vol. 4.1, 2010, pp. 208-209.

${ }^{22}$ Heinz Scheifinger, Hindu worship online and offline, în „Digital Religion... p. 125.

${ }^{23}$ Cheryl Anne Casey, Online Religion and Finding Faith on the Web: An Examination of Beliefnet.org în „Proceedings of the Media Ecology Association", Volume 2, 2001, p. 37. 
fizică a omului, stimulând în special mintea. Astfel, Fabrizio Vecoli afirmă că internetul pare să decorporalizeze omul asemenea Buddhismuluii ${ }^{24}$. Luisse Connelly afirmă că Buddha Center ca pagină a site-ului Second Life, oferă posibilitatea practicării cultului budist doar prin utilizarea simţurilor auditiv, vizual şi senzorial (doar la modul imitativ). În acest sens, există posibilitatea ca adoratorul să practice: tai chi, yoga, dans, discuții dharmice, meditație în linişte, cântatul, etc. În faţa calculatorului simţul vizual poate să copleşească celelalte simțuri, importanța căzând pe procesul cognitiv care poate să completeze activitatea senzorială şi să creeze conexiuni între creator şi participant ${ }^{25}$. Forța mentală promovată de Budhism are capacitatea să manipuleze atât corpul uman cu simțurile lui cât mediul înconjurător astfel încât să depăşească legile fizicii şi natura $^{26}$. Enigma relației dintre Budhismul offline şi eventuala cybersangha rămâne nedesluşită, iar posteritatea va putea da un verdict, ținând cont că practicarea cultului online îl denaturează pe cel tradițional foarte puțin.

\section{2. Mişcări neopăgâniste}

Ofensiva neopăgânismului în mediul online a cunoscut în ultimele decenii o evoluție semnificativă. Astfel, spațiul sacru al religiilor păgâne de mult apuse, s-a metamorfozat în spațiul sacru virtual.

După cum am arătat mai sus există adrese web care implică numeroase forme de ocultism, divinație, păgânism, etc., dintre care amintim:

\footnotetext{
${ }^{24}$ Fabrizio Vecoli, op. cit., p. 111.

${ }^{25}$ Louise Connelly, Virtual Buddhism: An Analysis of Aesthetics in Relation to Religious Practice within Second Life Dimensions, în „Heidelberg Journal of Religions on the Internet", vol. 4.1, 2010, pp. 22-31.

${ }^{26}$ Ibidem, p. 30.
} 
- Ritualul Online Wicca are ca scop înfăptuirea unei comunități care să resptecte regulile cultice, prin celebrarea sărbătorilor păgâne ${ }^{27}$.

- Vocea Vrăjitoarelor, care cu ajutorul paginii http://www.witchvox.com/, reîmprospătează memoria contemporană cu practici informații păgâne, formând adevărate e-comunități în acestora.

- Druidism Online (http://www.druidry.org/) oferă practicarea druidismului şi deasemenea făurirea anumitor comunităţi virtuale în care se poate integra internaut.

- Asociația Webcrafterilor (Artizanii internetului) Păgâni (thepwa.net). Această pagină web se doreşte a fi o uniune a surferilor păgâni care doresc o răspândire şi păgânizare a lumii virtuale prin ajutorul acordat înființării de noi site-uri cu conţinut păgân.

- Dansul (thedance.com) reprezintă o mixtură între occultism şi păgânism cu tente sataniste.

Aceste pagini web sunt doar o mică parte din ceea ce putem găsi în acest domeniu. Cu siguranță că neopăgânismul, într-un viitor nu foarte îndepărtat, va găsi mediu prielnic de răspândire internetul. Ar fi o imprudență dacă religiile tradiționale nu ar lua atitudine față de reapariția păgânismului pe internet, deoarece gradul mediatizării în spaţiul online este în creştere mai ales pentru religiile ,apuse”.

5. 3. Forme religioase cu conţinut SF

5. 3. 1. Matriximsul. Literatura şi cinematografia au dat naştere unor mişcări religioase în mediul virtual, cu un grad de originalitate ridicat. Astfel, apare în anul 2004 matrixismul, ca formă pseudo-

${ }^{27}$ Douglas E. Cowan i Jeffrey Hadden, Virtually Religious: New Religous Movements and the World Wide Web, în ,The Oxford Handbook of New Religious Movements", James R. Lewis (Editor), Oxford, New York, Oxford University Press, 2004, p. 130. 
religioasă inspirată din filmul fraţilor Wachowski. Matrixismul este exponentul unui soi de gnosticism, cu tentă sincretistă care are pretenția de a ghida umanitatea spre „mântuire”, asociind figura lui Iisus Hristos de cea a lui Mahomed, sau Neo (protagonistul Matrix), sau Luke Skywalker ${ }^{28}$. Foarte multe dintre aceste mişcări au instinctul relativizării oricărei forme religioase consacrate, cu dorinţa ascunsă de a ofensa creştinismul, pentru simplul motiv că aproape toate au ca loc de apariție teritoriul creştin.

5. 3. 2. Kopimism-ul este o religie care nu numai că s-a format cu ajutorul noii ideologii media, ci noua ideologie media este religie. Întemeietorul ei este Isak Gerson, care în 2010 pune bazele unui „ministeriu” misionar legitimat a cărui dogmă este distribuirea de documente pe Internet. Sistemul de valori al acestei congregații este bazat pe axiome care afirmă că Internetul este sfânt şi toată cunoaşterea este sacră, de aceea circulaţia cunoaşterii şi actul copierii este deasemenea sacru. Asistenţa pastorală individuală ca şi mărturisirea sunt făcute de către preoții kopimişti. Kopimismul transcende spre o cultură digitală trăită ca religie ${ }^{29}$. Divinizarea internetului în acest mod, reprezintă o cristalizare sau oficializare a tendinței idolatrizării internetului încă din zorii apariției lui.

5. 3. 3. Jedi-ismul, o ultimă mişcare analizată de noi, în ceea ce privește religiozitatea SF în mediul online, este jedi-ismul care apare în 2001 referindu-se la „spiritualitatea” jedi-ilor (călugări-cavaleri protagonişti ai filmului Star Wars). Acestă mişcare religioasă atrage (conform Recensământului din 2001) cca. 500000 persoane (din țări vorbitoare de limbă engleză) care îşi indică afilierea față de acest fenomen. Jediismul nu deține o ierarhie sau doctrină definite, însă se

\footnotetext{
${ }^{28}$ Fabrizio Vecoli, op. cit., p. 94-96.

${ }^{29}$ Laura Rutter Strickling, The Third Space and Beyond. Review of Digital religion: Understanding religious practice in new media worlds, în „Hyperrhiz: New Media Cultures", vol. 10, Fall, 2013, passim http://www.hyperrhiz.net/hyperrhiz10/book-media-reviews/the-third-spaceand-beyond-h-campbell-digital-religion.html accesat în data de 25.04.2015.
} 
disting câteva elemente sincretiste provenite din taoism şi o anumită etică medievală monastico-cavalerească ${ }^{30}$.

Ființa umană are libertatea de a-şi imagina absolut orice. Mircea Eliade spunea că formele experiențelor religioase viitoare pot fi complet distincte de ceea ce cunoaştem până acum. Era internetului este la început, aşa că religia şi internetul pot să „confecționeze” împreună noi şi noi forme care cu siguranță ne vor tăia respirația.

\section{Concluzii}

În primul rând, din punct de vedere dogmatic, Biserica este „familia" lui Dumnezeu pe pământ, născută „din apă şi din Duh”, care prin Taina Euharistiei se actualizează ca Trup Tainic al lui Hristos. Comunitatea (gemeinschaft) creştină se bazează pe relațiile interpersonale, în care fiecare persoană este responsabilă față de iubirea celeilalte.

Aşa cum Hristos a purtat trup şi a trăit în timp şi spațiu, tot aşa are „pretenția” ca Biserica Lui să rămână în timp şi spațiu reale, fizice. Ceea ce promovează cyberreligia reprezintă o formă actualizată de gnosticism, aş îndrăzni să spun un gnosticism tehnologic. Unii teologi sunt de părere că ,joaca de-a biserica pe internet pune în pericol mântuirea" ${ }^{31}$. După părerea noastră, apostazia secolului XXI nu se traduce numai prin renunţarea la propria convingere religioasă, ci amestecarea propriei religii cu alte doctrine şi practici. Prin urmare, creştinii care ajung să practice forme cultice necreştine, chiar în mediul online, îşi pierd identitatea religioasă.

Problema apariției noilor „experți” care „funcționează” ca lideri religioşi în mediul online o să acutizeze discordanța între exponenții religiilor consacrate şi webcrafterii religioşi, pe motiv că noile forme subminează atât autoritatea cât şi identitatea doctrinară a

\footnotetext{
${ }^{30}$ Fabrizio Vecoli, op. cit., pp. 99-102.

${ }^{31}$ Tim Hutchings, art. cit., p. 44.
} 
marilor religii. Chiar dacă sunt provenite din religiile consacrate, cyberreligiile vor rămâne în marea majoritate din cazuri, secte ,periculoase”.

Neopăgânismul care începe să se strecoare în mediul virtual, conduce spre o diversificare a „pieței religioase”, mai recent disponibilă şi online. Atomizarea sau individualizarea societăţii se hrăneşte profund din oferta $\mathrm{cu}$ care internetul se prezintă în fața omului post-modern, care caracterizat fiind de o religiozitate crepusculară, devine din consumator al „magazinului religios virtual” în obiect consumat. Internetul, ca ,sistem vascular” al globalizării ideilor şi informaţiei, contribuie pe deplin la răspândirea mai ales a religiilor apuse, care renasc cu o fațetă nouă, post-modernă.

\section{Bibliografie:}

1. Barker, Eileen, In and out of places: Varieties of Religious Locations in a Globalising World, în „Holy Nations and Global Identities: Civil Religion, Nationalism, and Globalisation", Annika Hvithamar, Margit Warburg şi Brian Arly Jacobsen (Edd.), Leiden, Boston, Edit. Brill, 2009.

2. Campbell, Heidi A., Understanding between Religion Online and Offline in a Networked Society, în ,Journal of the American Academy of Religion", Vol. 80, No. 1., Martie 2012.

3. Casey, Cheryl Anne, Online Religion and Finding Faith on the Web: An Examination of Beliefnet.org în „Proceedings of the Media Ecology Association", Volume 2, 2001.

4. Connelly, Louise, Virtual Buddhism: An Analysis of Aesthetics in Relation to Religious Practice within Second Life Dimensions, în „Heidelberg Journal of Religions on the Internet”, vol. 4.1, 2010.

5. Cornelio, Jayeel Serrano, The New Face of Global Evangelism: Virtualizing Spiritual Experience, în „Mediating Piety: Technology and Religion in Contemporary Asia", (Edited by Francis Khek Gee Lim), s. l., Brill Academic Publishers, 2009.

6. Cowan, Douglas E., şi Jeffrey Hadden, Virtually Religious: New Religous Movements and the World Wide Web, în „The Oxford Handbook of New Religious Movements", James R. Lewis (Editor), Oxford, New York, Oxford University Press, 2004. 
7. Diana Eck, Darśan - Seeing the Divine Image in India, Chambersburg, Anima Books, 1985.

8. Golan, Oren, Charting frontiers of online religious communities: The case of Chabad Jews, în „Digital Religion: Understanding Religious Practice in New Media Worlds", (Ed. Heidi A. Campbell), New York, Routledge, 2013.

9. Heinz Scheifinger, Hindu Embodiment and the Internet, Aesthetics and the Dimensions of the senses, în „Heidelberg Journal of Religions on the Internet", vol. 4.1, 2010.

10. Helland, Christopher, Popular religion and the World Wide Web: a Match Made in (Cyber) Heaven în „Religion Online: Finding Faith on the Internet", Lorne L. Dawson, Douglas E. Cowan (edd.), New York and London, ed. Routledge, 2004.

11. Hutchings, Tim, The Dis/Embodied Church: Worship, new media and the Body, în „Christianity in the Modern World”, (ed. Giselle Vincett, Elijah Obinna), Farnham, Ashgate, 2014.

12. Larsen, Elena, Cyberfaith: How Americans Pursue Religion Online, în „Religion Online: Finding Faith on the Internet”, Lorne L. Dawson, Douglas E. Cowan (edd.), New York and London, ed. Routledge, 2004.

13. Mc Luhan, Marshall, The Gutenberg Galaxy: the making of typographic man, First Edition, Toronto, University of Toronto Press Incorporated, 1962.

14. Papa Ioan Paul al II-lea, The Christian Message in a Computer Culture, în „Message of Holy Father John Paul II for the 24th World Communcation Day", Libreria Editrice Vaticana, Sunday 27 May 1990.

15. Strickling, Laura Rutter, The Third Space and Beyond. Review of Digital religion: Understanding religious practice in new media worlds, în „Hyperrhiz: New Media Cultures”, vol. 10, Fall, 2013.

16. Vecoli, Fabrizio, La religione ai tempi del web, Roma, Editori Laterza, 2013. 